\title{
DE LA COMPLEJIDAD JURÍDICA DE LOS VERTIMIENTOS*
}

\author{
Álvaro José Henao Mera** \\ Andrés Gómez-Rey***
}

Fecha de recepción: 20 de febrero de 2017

Fecha de evaluación: 6 de junio de 2017

Fecha de aprobación: 26 de octubre de 2017

Artículo de reflexión

DOI: http://dx.doi.org/10.18359/prole.3328

Forma de citación: Henao, A. J. \& Gómez-Rey, A. (2018). De la complejidad jurídica de los vertimientos. Revista Prolegómenos Derechos y Valores, 21, 41, 25-41. DOI: http://dx.doi.org/10.18359/prole.3328

\section{RESUMEN}

El presente artículo de reflexión analiza el modo como el Gobierno nacional en su afán de proteger los recursos naturales renovables, ha creado de manera desarticulada algunas reglas en relación con los vertimientos, generando en consecuencia, una inestabilidad en la jerarquía normativa y un desorden interpretativo en la forma de aplicar dichas normas por parte de las autoridades ambientales. Se tratarán entonces dos temas particulares: la necesidad de contar o no con permiso de vertimientos cuando estos son realizados a los sistemas de alcantarillado, $y$ las transiciones que sobre la norma de calidad de vertimientos (parámetros y valores límite máximos permisibles) se han desencadenado desde el 2010 hasta la fecha; a través de un estudio metodológico desde la dogmática jurídica.

\section{Palabras clave:}

Vertimientos, ambiental, permiso, parámetros y valores, máximos permisibles, transición normativa.

\footnotetext{
El presente escrito es producto del proyecto de investigación "La participación administrativa ambiental en los procedimientos para el otorgamiento de licencias ambientales", adelantado por la línea de investigación en Derecho Ambiental de la Universidad del Rosario, cuyo objetivo general es realizar una evaluación al ejercicio de los procesos para el otorgamiento de autorizaciones ambientales en Colombia y de esta forma, establecer resultados que señalen los vacíos que se han presentado en su implementación.

** Abogado y magíster en Derecho de la Universidad Icesi (Cali, Colombia), en la actualidad se desempeña como director general de la firma Manglar Abogados, dedicada a temas ambientales. Ha sido abogado de la Oficina Jurídica del Ministerio de Ambiente y Desarrollo Sostenible y profesor de cátedra en el área de Ordenamiento Territorial y Áreas Protegidas de la especialización en Derecho Ambiental de la Universidad Colegio Mayor de Nuestra Señora del Rosario (Bogotá, Colombia). Igualmente, ha sido docente de la Universidad Icesi y abogado de Parques Nacionales Naturales de Colombia. Correo electrónico: alvaro.henao@correo.icesi.edu.co

**** Abogado de la Universidad de La Sabana (Chía, Colombia), especialista en Derecho Ambiental y magíster en Derecho Administrativo de la Universidad Colegio Mayor de Nuestra Señora del Rosario (Bogotá, Colombia). Profesor de cátedra de pregrado y posgrado de diversas instituciones, entre ellas la Universidad Colegio Mayor de Nuestra Señora del Rosario, Icesi y Universidad de La Salle. Ha sido asesor de entidades como la Defensoría del Pueblo, la Superintendencia de Servicios Públicos Domiciliarios, algunas corporaciones autónomas regionales, el Ministerio de Ambiente y Desarrollo Sostenible, entre otras. De igual manera acompaña a empresas privadas en temas ambientales. Correo electrónico: andres.gomez@urosario.edu.co
} 


\section{THE LAW COMPLEXITY OF DUMPING}

\section{SUMMARY}

The hereby reflexing article analyses how the government way to protect renewable natural resources has created some disjointed rules with regard to dumping, generating as a consequence both instability within the normative hierarchy and an interpretative disorder when those legal rules are applied by environmental authorities. Therefore, two particular topics will be boarded in this article. First, whether or not it is necessary to acquire dump authorization when dumping into the sewerage system and second, whether or not the transitions upon the dumping quality law (parameters and maximum boundary permissible values) have been unleashed since 2010. This is going to be developed through a methodologic study from the legal dogmatic.

\section{Keywords:}

Dumping, environmental, license, parameter and values, permissible maximum, legal transition.

\section{DA COMPLEXIDADE JURÍDICA DOS VAZAMENTOS}

\section{RESUMO}

O presente artigo de reflexão analisa a forma como o Governo nacional, em sua ânsia de proteger os recursos naturais renováveis, tem criado de maneira desarticulada algumas regras em relação aos vazamentos, gerando, conseqüentemente, uma instabilidade na hierarquia normativa e uma desordem interpretativa na maneira em como aplicar esses padrões pelas autoridades ambientais. Serão abordados, então, dois temas específicos: a necessidade de ter ou não permissões de vazamentos quando são feitos nos sistemas de esgoto, e as transições que sob o padrão de qualidade de vazamentos (parâmetros e valores limite máximos permissíveis) tem-se desencadeado desde o 2010 até à data; através de um estudo metodológico desde a dogmática jurídica.

\section{Palavras chave:}

Vazamentos, ambiental, permissão, parâmetros e valores, máxima permissíveis, transição normativa.

\section{Introducción}

Alrededor del 70\%-75\% de la contaminación marina global es producto de las actividades humanas que tienen lugar en la superficie terrestre. Un $90 \%$ de los contaminantes es transportado por los ríos al mar. Por otro lado, entre un $70 \%$ y $80 \%$ de la población mundial (aproximadamente 3.6 billones de personas) se ubica en las costas o cerca de ellas, especialmente en zonas urbanas, donde una parte importante de los desechos que allí se producen se deposita directamente en el océano. Como consecuencia, muchos ecosistemas críticos, algunos únicos en el mundo, tales como bosques de manglar, arrecifes coralinos, lagunas costeras y otros [...] han sido alterados más allá de su capacidad de recuperación (Escobar, 2002, p.5 ).

Ante la realidad descrita, se ha hecho imperante establecer una regulación sobre las fuentes de contaminación líquida de los ríos y quebradas del país, con el fin de cumplir con los deberes constitucionales fijados por la Constitución Política de Colombia suscrita en 1991, según los cuales 
el Estado está en la obligación de proteger la diversidad e integridad del ambiente, conservar las áreas de especial valor ecológico y prevenir y controlar los factores de deterioro ambiental imponiendo las sanciones legales y exigiendo la reparación de los daños causados.

En virtud de lo anterior, nuestro ordenamiento jurídico ha dispuesto reglas específicas respecto de los vertimientos, que si bien son necesarias, en ocasiones desconocen algunos aspectos normativos y fácticos relevantes, lo cual se quiere demostrar en el presente artículo.

Para comenzar, recordemos que un vertimiento de conformidad con lo dispuesto en el artículo 2.2.3.3.1.3. del decreto 1076/2015 es la descarga final a un cuerpo de agua, un alcantarillado o al suelo, de elementos, sustancias o compuestos contenidos en un medio líquido, existiendo en consecuencia dos clases: uno puntual que se realiza a partir de un medio de conducción, del cual se puede precisar el punto exacto de descarga al cuerpo de agua, alcantarillado o al suelo; y otro no puntual, o aquel en el que no se puede precisar el punto exacto de descarga al cuerpo de agua o al suelo.

Siendo el vertimiento la acción de arrojar residuos o desechos líquidos, según el artículo 8 del decreto ley 2811/1974 es un factor de contaminación, por lo cual es una actividad que requiere de la obtención de un permiso o autorización administrativa que otorga la institucionalidad ambiental. Por ello el artículo 2.2.3.2.20.1. del decreto único del sector ambiente, establece que el vertimiento solo podrá ser dispuesto en las aguas clase II, es decir, por fuera de las cabeceras de las fuentes, las aguas subterráneas, las aguas costeras usadas para recreación, las aguas arriba de las bocatomas y las áreas protegidas. Sin embargo, en donde esté permitido el vertimiento, se deberá siempre efectuar con tratamiento previo, acatando las reglas del decreto 1076/2015, que contempla entre otros: regulación de usos y calidad del agua, ordenación de cuencas y lo asociado con vertimientos.

El permiso a cargo de la institucionalidad ambiental tiene a su vez, como fin, analizar tres variables principales: (i) la carga contaminante entendida como "el producto de la concentración básica promedio de una sustancia por el caudal volumétrico promedio del líquido que la contiene determinado en el mismo sitio" según el decreto 3930 de 2010 (hoy compilado en el decreto 1076 de 2015), (ii) la eficiencia y eficacia del sistema de tratamiento que permitirá el cumplimiento de los parámetros máximos permisibles por el ordenamiento y (iii) la capacidad del cuerpo receptor. Así pues, cada usuario deberá cumplir con una norma de vertimientos o remoción de dicha carga.

No obstante, según la legislación actual, no es del todo claro si se requiere o no permiso de vertimientos cuando estos se lleven al alcantarillado, situación que se desea estudiar aquí. Más allá de esto, con el propósito de mostrar la dispersa regulación sobre la materia, también se examinarán los regímenes de transición en relación con los parámetros máximos permisibles de vertimientos a las aguas superficiales.

Sobre este punto debe tenerse en cuenta que el Gobierno nacional en cabeza del Ministerio de Ambiente y Desarrollo Sostenible, ha venido emitiendo normas que plantean diferentes niveles máximos permisibles de contaminación líquida, la cual varía según la actividad industrial, comercial o de servicios realizada. A manera de ejemplo la empresa prestadora del servicio público de alcantarillado debe cumplir con unos parámetros de remoción específicos. Con todo, la normatividad expedida, además de contener reglas complejas de cumplir por parte de los administrados, ha instituido regímenes de transición confusos, ambiguos y en ocasiones incoherentes frente a las normas de superior jerarquía existentes, como es el caso de la resolución 631/2015.

Sin embargo, las reglas y particularidades que han cobijado las condiciones y obligaciones en torno a los vertimientos han lucido un especial desorden normativo que se pretende mostrar en este artículo, con el fin de develar esta problemática y llamar la atención del regulador para determinar normativamente un asunto trascendental para el país, y para generar en 
los administrados seguridad jurídica que ayude a tener claro en todo momento las regulaciones sobre tal aspecto.

El documento se divide en dos secciones, la primera incumbe a la obligatoriedad o no de obtener permiso de vertimientos cuando estos sean hechos al alcantarillado, y la segunda estudia las transiciones que la dispersión normativa creó respecto de la norma que decreta los parámetros máximos de calidad cuando el vertimiento se ejecute en aguas superficiales, terminando con la recopilación in genere de lo observado.

En consideración de la escasa doctrina existente sobre la temática a discutir ${ }^{1}$, se propone una metodología desde la dogmática jurídica, en concreto, sobre la comprensión y análisis de la ley y la jurisprudencia. Nótese sin embargo, que se realizará a continuación un tratamiento tecnócrata, buscando sirva de base para posteriores investigaciones $y$, por ende, puede parecer un examen sucinto, ya que se desea principalmente exponer una especial problematización sobre la materia.

\section{A. De la necesidad de contar con permiso de vertimientos al alcantarillado}

El artículo 41 del derogado decreto 3930/2010² ordenaba que:

Toda persona natural o jurídica cuya actividad o servicio genere vertimientos a las aguas superficiales, marinas, o al suelo, deberá solicitar y tramitar ante la autoridad ambiental competente, el respectivo permiso de vertimientos

1 A pesar de esto, véanse las connotaciones básicas de los vertimientos en: Macías (1998), Morales (1999), Escobar (2002), Santander (2002), González (2004) y Rodríguez, Lozano y Gómez-Rey (2011).

2 El epígrafe del decreto reza: "Por el cual se reglamenta parcialmente el Título I de la Ley $9^{a}$ de 1979, así como el Capítulo II del Título VI -Parte III- Libro II del Decretoley 2811 de 1974 en cuanto a usos del agua y residuos líquidos y se dictan otras disposiciones". Así pues, se trató del decreto que recoge las líneas generales sobre los vertimientos en Colombia.
Parágrafo $1^{\circ}$. Se exceptúan del permiso de vertimiento a los usuarios y/o suscriptores que estén conectados a un sistema de alcantarillado público [...]

De la lectura de la norma se entiende que requiere permiso de vertimientos cualquier persona que realice una descarga de desechos líquidos que recaiga sobre tres posibles objetos: las aguas superficiales, la mar y el suelo. La descarga a ningún otro lugar demandará entonces, permiso de vertimientos. Por esta razón, el parágrafo explicaba que las descargas al alcantarillado no necesitaban permiso de vertimientos, es decir que, a nuestro juicio, el parágrafo era simplemente aclarativo mas no contenía excepciones, pues no decía nada diferente al contenido del artículo expuesto.

La razón que justifica que las descargas que los suscriptores realizan al sistema de alcantarillado no urjan de permiso de vertimientos es que el prestador del servicio público domiciliario de alcantarillado está en la obligación de obtener dicha autorización, tal y como lo dispone el artículo $25^{3}$ de la ley 142/19944, y de elaborar un plan de saneamiento y manejo de vertimientos ${ }^{5}$ (Corporación Autónoma Regional de Cundina-

Artículo 25. "Concesiones, y permisos ambientales y sanitarios. Quienes presten servicios públicos requieren contratos de concesión, con las autoridades competentes según la ley, para usar las aguas; para usar el espectro electromagnético en la prestación de servicios públicos requerirán licencia o contrato de concesión [...]".

4 Esto por cuanto el prestador es quien hará la descarga de residuos principalmente líquidos a los recursos naturales renovables como el agua superficial o la mar.

5 La Corporación Autónoma Regional de Cundinamarca en su Guía para la formulación del plan de saneamiento y manejo de vertimientos, afirma que es "el conjunto de programas, proyectos y actividades, con sus respectivos cronogramas e inversiones necesarias para avanzar en el saneamiento y tratamiento de los vertimientos, incluyendo la recolección, transporte, tratamiento y disposición final de las aguas residuales descargadas al sistema público de alcantarillado, tanto sanitario como pluvial, los cuales deberán estar articulados con los objetivos y las metas de calidad y uso que defina la autoridad ambiental competente para la corriente, tramo o cuerpo de agua [...]" (2006, p-18). 
marca, 2006) ${ }^{6}$. Asimismo, le corresponde a dicho prestador, entregar los vertimientos a fuentes superficiales, con el cumplimiento de los parámetros y límites permisibles que registra la norma. Luego, el parágrafo en cita fue demandado en nulidad por cuanto

[... ] a juicio de la parte actora, con la vigencia del acto acusado se violan de manera ostensible los artículos 286, 287, 288, 298, 311 y 322 de la Constitución Política, el artículo $1^{\circ}$ del Decreto 1421 de 1993 y los artículos 65 y 66 de la Ley 99 de 1993 [...].

Resalta el texto de la demanda que se vulnera el artículo 11 de la ley 9/1979 que reza: "Antes de instalar cualquier establecimiento industrial, la persona interesada deberá solicitar y obtener del Ministerio de Salud o de la entidad en quien este delegue, autorización para verter los residuos líquidos", así como el artículo 132 del decreto ley 2811/1974 que manifiesta:

Sin permiso, no se podrán alterar los cauces, ni el régimen y la calidad de las aguas, ni interferir su uso legítimo. Se negará el permiso cuando la obra implique peligro para la colectividad, o para los recursos naturales, la seguridad interior o exterior o la soberanía nacional.

Las razones principales para sostener que el derogado parágrafo 1 del artículo 41 del decreto 3930/2010 violentaba el ordenamiento jurídico y era nulo, las sintetiza el Consejo de Estado indicando que el presidente de la República desbordó sus competencias al emitir el acto acusado ya que "ni en el Código Sanitario Único, ni en el Código Nacional de los Recursos Naturales Renovables, normas objeto de reglamentación parcial en la decisión enjuiciada, se prevé excepción alguna frente a la obtención del permiso de vertimientos [...]" (Consejo de Estado, 2011) por lo cual aseguró que era

$6 \quad$ Por ello, el parágrafo del artículo 41 ya citado explicaba que no se requería permiso de vertimientos cuando estos se llevaran a cabo sobre el alcantarillado (por cuanto esto estaba así dispuesto en su contenido y no estaba creando una excepción).
[...] evidente la contradicción anotada, pues las normas en ningún momento han habilitado la supresión del permiso de vertimientos al sistema de alcantarillado, por el contrario, son expresas en indicar la necesidad de permiso en todo vertimiento que se genere en el recurso hídrico [... (Consejo de Estado, 2011).

En consecuencia, el Consejo de Estado (2011) decidió suspender provisionalmente el parágrafo 1 del artículo 41 del decreto 3930/2010 indicando que:

[...] por simple comparación normativa, es evidente la violación que aduce el actor del aparte censurado, toda vez que allí se exceptúa del requerimiento de obtener permiso de vertimiento, a los usuarios y/o suscriptores que se encuentren conectados a un sistema de alcantarillado público, salvedad esta que no contempla la Ley [...].

Con ello intentó argumentar que la ley 9/1979 no podía ser excepcionada con un decreto ${ }^{7}$, en virtud de la jerarquía normativa que rige el accionar en nuestro ordenamiento jurídico.

Sobre este particular se debe resaltar que el Consejo de Estado se abstuvo de analizar los presupuestos de cada una de las normas presuntamente vulneradas y no tuvo en cuenta que: (i) el decreto 3930/2010 en el parágrafo citado regulaba "quienes deben obtener el permiso de vertimientos" y que el Código de Recursos Naturales se refiere a la necesidad de contar con permiso para "alterar los cauces", lo cual dista sustancialmente de realizar vertimientos al alcantarillado y (ii) la ley 9/1979 fija como requisito previo a la "instalación" de establecimientos

Dijo el Consejo de Estado: "En el escenario propuesto por el Gobierno Nacional, se reiteran los condicionamientos establecidos mediante ley, no obstante, también determina una excepción que nunca contempló el Congreso de la República, cual es, la de exceptuar a las personas naturales o jurídicas cuya actividad o servicio genere vertimientos a las aguas superficiales, marinas o al suelo, de obtener el permiso respectivo, cuando tales personas se encuentren conectadas a un sistema de alcantarillado público [...]". (Consejo de Estado, 2011) 
industriales que viertan residuos líquidos la obtención de una autorización, cuando a ello se esté obligado.

Lo que igualmente se trata de una situación diferente, ya que: (i) el permiso de vertimientos no es para "instalar establecimientos industriales", es decir, una cosa es necesitar permiso para verter y otra requerir autorización para instalar establecimientos industriales que potencialmente deban realizar vertimientos ${ }^{8}$; (ii) el código sanitario no especifica cuál es dicha autorización, siendo curioso que la norma de salud solicitara un permiso ambiental y se preocupara en consecuencia por las redes de alcantarillado y no tanto por la calidad de las aguas de las fuentes superficiales.

Ahora bien, con la suspensión provisional del parágrafo del artículo 41 en mención, este deja de surtir efectos jurídicos, quedando únicamente en el ordenamiento jurídico el cuerpo del artículo 41 precitado, del cual se deduce que no se exige permiso de vertimientos cuando la descarga se efectúe al alcantarillado, por cuanto no es un presupuesto normativo que allí se contemple.

Curiosamente, la Oficina Jurídica del Ministerio de Ambiente y Desarrollo Sostenible en concepto 8140 e227306 del 12 de septiembre de 2014 consideró que:

[...] las Autoridades Ambientales con base en los (sic) dispuesto en los artículos 11 de la Ley 9 de 1979, 132 del Decreto 2811 de 1974 y Decreto 3930 de 2010, actualmente tienen la competencia para exigir permiso de vertimientos a los usuarios $\mathrm{y} / \mathrm{o}$ suscriptores que estén conectados a un sistema de alcantarillado público, hasta tanto el Consejo de

8 Se cita a manera de ejemplo que determinar que la autorización para instalar establecimientos industriales es el permiso de vertimientos y que por esto es exigible este último; implicaría cosas como que, una vivienda conectada a la red de alcantarillado es un establecimiento industrial y por ello requiere permiso de vertimiento. En otras palabras, lo que se desea mostrar es que la imprecisión en la utilización de escuelas o sistemas estrictos de interpretación jurídica, tendría como consecuencia errores de lógica y deontológicos.
Estado emita un pronunciamiento de fondo sobre este asunto [...].

Con esta postura el Ministerio de Ambiente adicionó el contenido del cuerpo del artículo 41 del decreto 3930/2010 incluyendo que se exige permiso de vertimientos cuando la descarga se realice al alcantarillado. Situación que además de no tener sustento en el ordenamiento, tampoco tiene una intención de dotar de mayor protección al ambiente, pues es claro que los usuarios industriales que hagan vertimientos de aguas residuales no domésticas están en la obligación de presentar la caracterización a las empresas prestadoras del servicio público, cumpliendo además la norma de vertimiento existente. De hecho, el artículo 2.2.3.2.21.4 fija que "en todo sistema de alcantarillado se deberán someter los residuos líquidos a un tratamiento que garantice la conservación de las características de la corriente receptora", situación que le corresponde al prestador del servicio y no al generador del vertimiento.

De esta manera, es dable afirmar que esta posición es discutible, ya que el alcantarillado como receptor de vertimientos no aparece fijado en la norma y por ende no requiere permiso. Ahora, en caso de ser jurídicamente vinculante la opinión del Ministerio de Ambiente y Desarrollo Sostenible, tendríamos entonces que todos los suscriptores del servicio público domiciliario de alcantarillado necesitan permiso de vertimientos, es decir, todas las unidades habitacionales (casas, edificios, apartamentos, oficinas, industrias, colegios, entre otros) requieren de esta autorización administrativa. Más aún, toda unidad habitacional, de servicios, oficial o dotacional debería ser considerada "establecimiento industrial".

Posteriormente, el Gobierno nacional expidió el decreto 1076/2015 en el que se compilaron y derogaron ${ }^{9}$ todos los decretos reglamentarios del

$9 \quad$ Asegura el artículo 3.1.1. del decreto único que quedan excluidas de esa derogatoria las normas de naturaleza reglamentaria de este sector administrativo que, a la fecha de expedición del presente decreto, estén suspendidas por la Jurisdicción Contencioso Administrativa, las cuales se compilarán en este decreto, en caso de recuperar su eficacia jurídica. 
sector ambiente y desarrollo sostenible, en donde su artículo 2.2.3.3.5.1. reprodujo el artículo 41 del decreto 3930/2010 pero excluyó su parágrafo 1 , en virtud de la suspensión provisional que efectuó el Consejo de Estado.

Con ello entonces, el ordenamiento jurídico actual cuenta únicamente con el cuerpo del artículo 41, hoy el 2.2.3.3.5.1, allí se establece que deberá tramitar y obtener permiso de vertimientos cualquier persona que realice la descarga de residuos principalmente líquidos al suelo, la mar o las aguas superficiales; resaltando nuevamente que en dicha norma no se encuentra el alcantarillado.

Teniendo en cuenta que solicitarle permiso de vertimientos a todos los suscriptores del servicio público de alcantarillado (domésticos, industriales y otros) desborda la capacidad de las autoridades ambientales y pareciera innecesario, pues el prestador es quien debe obtener dicha autorización administrativa, la Oficina Asesora Jurídica del Ministerio de Ambiente y Desarrollo Sostenible mediante nuevo concepto, 8140-E2-23685 del 30 de julio 2015, luego de haber adicionado vía concepto el artículo 2.2.3.3.5.1. del decreto 1076/2015, lo excepciona parcialmente al establecer que únicamente requieren permiso de vertimientos al alcantarillado los suscriptores no domésticos, es decir los comerciales, industriales, oficiales y especiales.

Reza el concepto "a la autoridad ambiental le compete exigir el permiso de vertimientos a quienes vierten aguas residuales no domésticas a la red de alcantarillado e igualmente el cumplimiento de los parámetros y límites máximos permisibles [...]"10. Siendo pues esta la realidad actual del Sistema Nacional Ambiental.

A pesar de lo mencionado en el concepto fijado, el artículo 8 de la resolución 0631/2015 deter-

10 Se debe aclarar que si bien el decreto 3930/2010 hoy compilado en el decreto 1076/2015 no exigió el permiso de vertimientos a los suscriptores del servicio, sí obligó a que quienes hagan vertimientos no domésticos, como los industriales, cumplieran con la norma de parámetros máximos permisibles. mina los parámetros fisicoquímicos y sus valores límites máximos permisibles en los vertimientos puntuales de aguas residuales domésticas de las actividades industriales, comerciales o de servicios, lo cual incluiría el cumplimiento de los parámetros y límites máximos permisibles a los generadores de aguas residuales domésticas. De lo dicho tenemos:

- Que el ordenamiento jurídico actualmente posee una norma (artículo 2.2.3.3.5.1. del decreto 1076/2015) en donde no se exige permiso de vertimientos a quien realice la descarga final de residuos líquidos a un alcantarillado.

- Que vía concepto, el Ministerio de Ambiente y Desarrollo Sostenible adicionó esta norma, indicando que sí debe tener permiso de vertimientos quien realice la descarga al alcantarillado.

- Que vía concepto, la Oficina Jurídica del Ministerio aclaró luego que esta obligación únicamente procede para suscriptores que realicen vertimientos no domésticos.

- Que en todo caso, el cumplimiento de los parámetros y límites máximos permisibles le corresponde tanto a los suscriptores, como al prestador del servicio, generando en consecuencia el doble cumplimiento de un requisito normativo.

Con lo dicho, más que una reflexión crítica sobre el tema, se desea llamar la atención sobre la necesidad de regular coherentemente lo relacionado con los vertimientos, ya que en el caso presentado evidenciamos entre otros: (i) un mal diseño de la norma inicial, (ii) una inadecuada interpretación judicial sobre la norma, (iii) una adición parcial vía concepto de la norma (lo que desborda las competencias de la Oficina Jurídica del Ministerio) y (iv) un desorden institucional dado el diverso comportamiento de las autoridades ambientales, que sin duda termina poniendo en riesgo la seguridad jurídica de los administrados. 
No obstante, las complicaciones creadas a los sectores derivados del tema de vertimientos van más allá de la mera necesidad de contar o no con un permiso ${ }^{11}$. Por esto a continuación se expondrá cómo la historia de las normas que regulan el tema han tenido indeseables consecuencias.

\section{B. El régimen de transición en la normatividad de vertimientos}

El manejo de los vertimientos en el ámbito ambiental ha tenido una importante evolución en la legislación colombiana. Desde la expedición del Código Nacional de Recursos Naturales Renovables y de Protección al Medio Ambiente, se determinó en el capítulo sobre usos urbanos, habitacionales e industriales que se debían evitar aquellos vertimientos no controlables que causen molestias o daños a los núcleos humanos, a los suelos, a las aguas, a la fauna, al aire o a la flora del área.

Sin embargo fue hasta 1984 que el Gobierno emitiría verdaderas normas sobre la materia, con la expedición del decreto 1594. Este decreto en su momento estableció entre otros:

- Prohibiciones absolutas de verter, como en las cabeceras de las fuentes de agua.

- La clasificación de los vertimientos entre puntuales y no puntuales.

- La clasificación de los usuarios entre existentes y nuevos ${ }^{12}$.

- Tuvo en su momento una norma de calidad de parámetros máximos de vertimientos.

11 A parte del tema que se tratará enseguida, piénsese que en la actualidad también se solicita permiso de vertimientos al alcantarillado a quienes "tengan infraestructura instalada" para efectuar el vertimiento, aunque no lo estén realizando. Es decir, el tema posee muchos inconvenientes y problemáticas dada la regulación deficiente.

12 Esto es, antes de junio de 1984 -existentes-y aquellos que viertan en vigor de la nueva norma -nuevos-.
Rodríguez et al. (2011) explican en su libro La protección jurídica del agua en Colombia que este decreto pedía que el porcentaje de remoción del material contaminante fuese de un ochenta por ciento ${ }^{13}$, lo cual privilegiaba unas actividades sobre otras. Dicen estos autores que al comparar el veinte por ciento de la actividad doméstica con el de un relleno sanitario; por dar una estadística sin fundamento pero sumamente ilustrativa, unos mil usuarios de actividad doméstica sin tratamiento equivalen al veinte por ciento de la actividad del relleno ${ }^{14}$. Después se expidió el decreto 3930/2010 en donde se contemplaron reglas como:

- La consagración expresa del principio de rigor subsidiario ${ }^{15}$.

- La consideración que los usuarios antiguos que amplíen su producción serán reconocidos como usuarios nuevos.

- Que "el Ministerio de Ambiente, Vivienda y Desarrollo Territorial dentro de los dieciocho (18) meses contados a partir de la publicación del presente decreto, definirá los criterios de calidad para el uso de las aguas superficiales, subterráneas y marinas [...]", con ello indicando que una vez se expidiera esta nueva norma de calidad, quedarían derogadas las reglas del decreto 1594/1984.

- Requisitos y trámites novedosos para la obtención del permiso.

13 Y otros ya descritos en porcentaje.

14 Continúan igualmente explicando que "el tope máximo legal es subjetivo y no controla satisfactoriamente a los beneficiarios de este permiso. En suma, vemos que el principio de igualdad puede llegar a verse violentado a partir de dos criterios, por el favorecimiento que la legislación hace a los usuarios existentes y por qué el porcentaje de remoción no tiene en cuenta la actividad que se desarrolla como criterio o variable especial para la imposición de la norma [...]" (Rodríguez et al., 2011, p. 192).

15 Según el artículo 21 del Decreto 3930 de 2010: "Rigor subsidiario para definir los criterios de calidad del recurso hídrico. La autoridad ambiental competente, con fundamento en el artículo 63 de la Ley 99 de 1993, podrá hacer más estrictos los criterios de calidad de agua para los distintos usos previa la realización del estudio técnico que lo justifique". 
- La introducción al ordenamiento de dos "programas", que buscaron que los usuarios se adaptaran a las nuevas reglas, a saber:

- Plan de Reconversión a Tecnologías Limpias en Gestión de Vertimientos, para aquellos que a la entrada del decreto 3930/2010 tuviesen permiso de vertimientos ${ }^{16}$.

- Plan de cumplimiento, para aquellos usuarios que a la entrada en vigencia del decreto 3930/2010 no tuviesen permiso de vertimientos ${ }^{17}$.

Empero, el Ministerio de Ambiente no expidió las nuevas normas o parámetros de calidad para vertimientos en el año 2012 como lo ordenaba el decreto 3930/2010, demorándose hasta el 2015 en donde conocimos la resolución 631, que trajo diversas situaciones que vale la pena destacar:

16 Es una posibilidad que tenían las empresas para establecer mecanismos que propendieran por la reconversión tecnológica de los procesos productivos, y con ellos se lograra el mejoramiento y consecuente cumplimiento de los parámetros máximos límites permisibles. Los objetivos de este plan se basaban en la reducción y minimización de la carga contaminante por unidad de producción o la reutilización y el reciclaje de los subproductos o materias primas por unidad de producción, o incorporar a los procesos de producción materiales reciclados, asociados con la generación de vertimientos.

De conformidad con el artículo 61 del mencionado decreto (artículo 2.2.3.3.6.1 del decreto 1076/2015), el plan podría ser presentado dentro del primer año previsto en el artículo 77, es decir, en el periodo comprendido entre el 1 de enero de 2016 y el 1 de enero de 2017.

17 El artículo 52 del decreto 3930/2010 (modificado por el artículo 4 del decreto 4728/2010) hoy compilado en el artículo 2.2.3.3.5.12 del decreto 1076/2015 declara que la autoridad ambiental requerirá al administrado para que presente un plan de cumplimiento cuando se concluya la no viabilidad de otorgar el permiso de vertimiento al cuerpo de agua o al suelo conforme a la evaluación técnica y documental realizada por la autoridad.

Es claro que, del contenido del artículo, se entiende que los planes de cumplimiento son exigibles únicamente a quienes se les ha negado el permiso de vertimientos, y no a aquellos que hayan incumplido con la normatividad vigente.
- Los parámetros que se registran en la resolución 631/2015 son sustancialmente diferentes a aquellos que aparecen en el decreto 1594/1984, y tienen una clara división dependiendo de cada sector industrial, situación que no se presentaba en el decreto de 1984.

- La resolución 0631/2015 no instituyó normas de calidad o parámetros máximos para los vertimientos que se lleven a cabo en aguas de la mar, lo cual genera que aún continúe vigente la disposición contenida en el decreto 1594/1984. Similar circunstancia ocurre con los parámetros sobre vertimientos a suelo, pues al no haber sido expedida por el Ministerio, cada autoridad ambiental posee absoluta discrecionalidad para su establecimiento, encontrando algunos casos en los que la autoridad ambiental simplemente no adelanta procedimientos que permiten o no el vertimiento al suelo.

- Los diversos planes que el decreto 3930/2010 diseñó para "permitir" que los sectores industriales se adaptaran a las nuevas reglas, es decir, los planes de cumplimiento y los planes de reconversión a tecnologías limpias, buscaban fundar mecanismos para que las empresas pudieran adoptar el cumplimiento de los valores referidos. Sin embargo, el hecho de que la norma de vertimientos haya sido expedida en una fecha y entrado en vigor en otra, hizo que muchas empresas no pudieran acceder a tal beneficio, o que las autoridades ambientales presentaran confusiones relacionadas con las fechas posibles de recepción de los mismos.

- El régimen de transición establecido para el cumplimiento de la resolución 0631/2015 se supeditó a la existencia de un permiso de vertimientos, permiso sin el que los usuarios debían cumplir de manera inmediata la norma fijada a partir de su fecha de entrada en vigencia (1 de enero de 2016), sin importar la discusión sostenida en el primer aparte de este artículo. 
Sobre la fecha de aplicabilidad del régimen de transición ${ }^{18}$ y su importancia para los administrados se hará alusión a continuación, fijando de manera expresa la opinión de los autores sobre el particular.

En primer lugar, se debe recordar que uno de los elementos más relevantes al momento de definir la aplicabilidad de una norma, es la evaluación de la fecha de su publicación en el Diario Oficial ${ }^{19}$, como claramente lo revela la normatividad y la jurisprudencia referente. A modo de ejemplo la Corte Constitucional colombiana en la sentencia C-957/1999 (M. P.: Álvaro Tafur Galvis) consignó que es a partir de la fecha de publicación en el Diario Oficial que la norma comienza a producir efectos jurídicos.

Igualmente ocurre tratándose de actos administrativos de carácter general (entiéndanse decretos y resoluciones dirigidos a una comunidad indeterminada), en donde se insiste en que los mismos existen y son válidos desde el momento de su expedición, pero no producen efectos jurídicos hasta que el acto administrativo haya sido publicado en el Diario Oficial, pues esta publicación le otorga la oponibilidad frente a terceros y define su vigencia.

Un segundo escenario que puede darse y que es muy usual, es en el que el administrador determina que la norma entrará en vigencia en una fecha posterior a su publicación en el Diario Oficial, esto es, que a pesar de que la norma

18 "[...] la Real Academia de la Lengua Española (2016) expresa que por régimen debe entenderse el conjunto de normas que gobiernan o rigen una cosa o una actividad y por transición 'la acción y efecto de pasar de un modo de ser o estar a otro distinto'; por lo cual podemos afirmar que un régimen de transición normativo se trata de un articulado específico que permite la adaptación en el tiempo de las condiciones de una regulación anterior a una posterior, permitiendo que mientras esto ocurre, se sostengan como válidas las primeras para quienes en dicha época hubiesen cumplido los preceptos o requisitos que la ley contenía [...]" (Gómez-Rey, Rincón y Rodríguez, 2016. P. 164).

19 El artículo 119 de la ley 489/1989 sostiene que "Únicamente con la publicación que de los actos administrativos de carácter general se haga en el Diario Oficial, se cumple con el requisito de publicidad para efectos de su vigencia y oponibilidad". exista y sea oponible, únicamente producirá sus efectos al momento de entrar en vigor en la fecha previamente seleccionada.

Al respecto, la Sala Plena de la Corte Constitucional en la sentencia C-957/1999 falló que por regla general la ley comienza a regir a partir de su promulgación, salvo que el legislador mediante precepto expreso convenga una fecha diferente a aquella, pues los efectos jurídicos de las leyes que se producen dan lugar a su oponibilidad y obligatoriedad a partir de la promulgación en el Diario Oficial, sin que por ello se afecte la validez ni la existencia de los mismos.

Por su parte, la misma Corte Constitucional en la sentencia C-932/2006 (M. P.: Humberto Antonio Sierra Porto) estipuló con referencia a la vigencia de la ley, que es aquella figura que le concede la eficacia jurídica (entendida como obligatoriedad y oponibilidad), ya que desde una perspectiva cronológica o temporal, a partir de su entrada en vigor se produce la generación de efectos jurídicos obligatorios por parte de la norma. De esta forma, si la ley fija una fecha de inicio diferente a su publicación, no será la fecha de publicación la que determine su puesta en práctica.

Así, se logra concluir que la Corte resalta en estos casos, que si el legislador o el administrador decide postergar la entrada en vigencia de la norma, posterga igualmente los efectos jurídicos predicables de la misma, lo cual además de ser un criterio jurídico válido, parece ser un criterio lógico, puesto que mal haría en definir efectos de una norma a sabiendas que la misma no ha entrado en vigor.

Respecto al tema del régimen de transición establecido en la norma de vertimiento, se debe considerar a partir de qué momento conviene contar los términos fijados en dicha disposición. De conformidad con lo anterior, en este acápite se desarrollará la normatividad aplicable para tal efecto, y se determinarán los criterios de interpretación asumidos sobre la base de dicho régimen. 
Por ello, es menester ejecutar un recuento cronológico del asunto. Lo primero que se debe advertir es que el 17 de marzo de 2015, el Ministerio de Ambiente y Desarrollo Sostenible expidió la resolución 0631/2015 "Por la cual se establecen los parámetros y los valores límites máximos permisibles en los vertimientos puntuales a cuerpos de aguas superficiales y a los sistemas de alcantarillado público y se dictan otras disposiciones", que se publicó en el Diario Oficial 49.486 el 18 de abril de 2015. Esta resolución tuvo dos particularidades: (i) "sujetar" o suspender su vigencia hasta el 1 de enero de 2016, por cuanto así lo dispuso su artículo 21 y (ii) establecer que para su interpretación se debe aplicar el régimen de transición que se detalla en el artículo 77 del decreto 3930/2010, modificado por el artículo 7 del decreto 4728/2910, y finalmente compilado en el artículo 2.2.3.3.11.1 del decreto 1076/2015, que ordena que las normas de vertimientos que expida el Ministerio serán aplicables a los generadores de vertimientos en todo el territorio colombiano.

De esta manera se dispuso lo siguiente conforme al artículo 77 descrito:

1. Para acceder al régimen de transición se debe contar con permiso de vertimientos vigente al momento de entrada en vigor de la resolución 0631/2015.

2. La caracterización hecha en el año inmediatamente anterior a la entrada en vigencia de la resolución, es decir, la caracterización de vertimientos del año 2015, acordará los plazos del régimen de transición así:

i. Si al año 2015 se cumplía con los parámetros y límites permisibles establecidos en el decreto 1594/1984, se deberá dar cumplimiento a los límites de la resolución 0631/2015, dos años después de la entrada en vigencia de la misma.

ii. Si al año 2015 no se cumplía con los parámetros y límites permisibles establecidos en el decreto 1594/1984, se deberá dar cumplimiento a los límites de la resolución
0631/2015 dieciocho meses después de la entrada en vigor de la misma.

ii. Los tiempos mencionados se podrán incrementar en tres años (en el caso i) o en dos años (en el caso ii) en caso de contar con un plan de reconversión a tecnologías limpias aprobado por la autoridad ambiental en los tiempos correspondientes por ley.

Dicha posición en plazos, hizo que aquellos usuarios que no contaban con permiso de vertimiento vigente, solicitaran a las autoridades ambientales la expedición del mismo, pues les permitiría acogerse al régimen de transición. Asimismo lo hicieron quienes tenían conectados sus vertimientos a las redes del alcantarillado, los cuales si bien ya venían cumpliendo con la normatividad del decreto 1594/1984, deberían ajustarse a los nuevos límites y parámetros permisibles.

La anterior situación hizo que las autoridades ambientales colapsaran en trámites, razón por la que el Ministerio de Ambiente y Desarrollo Sostenible expidió la resolución 2659/2015, en donde se expresaba ampliar el término de entrada en vigencia de la resolución 0631/2015 al 1 de mayo de 2016, tan solo para aquellos usuarios del servicio de alcantarillado que hubieran entregado la solicitud completa de permiso de vertimientos antes de la entrada en vigencia de la resolución 0631/2015, y la autoridad ambiental no se hubiera pronunciado al 31 de diciembre de 2015.

Debe hacerse alusión en este punto a que se presentan varias fechas que pueden generar confusión en la norma: (i) fecha de publicación de la norma de vertimientos: 18 de abril de 2015; (ii) fecha de entrada en vigencia de la norma de vertimientos: 1 de enero de 2016; y (iii) ampliación de la norma de vertimientos: 1 de mayo de 2016.

Así las cosas, si se cuenta únicamente las fechas aplicables conforme a la fecha de publicación de la resolución, tendríamos el escenario que se muestra en la tabla 1. 
Tabla 1. Fechas aplicables para el régimen de transición contadas a partir del 18 de abril de 2015

\begin{tabular}{l|l|l}
\hline $\begin{array}{l}\text { Situación frente al plan de reconver- } \\
\text { sión a tecnologías limpias }\end{array}$ & $\begin{array}{c}\text { Estado de cumplimiento del } \\
\text { decreto 1594/1984 }\end{array}$ & $\begin{array}{c}\text { Fecha de entrada en vigencia } \\
\text { de la resolución 631/2015 }\end{array}$ \\
\hline $\begin{array}{lll}\text { Sin plan de reconversión a tecnologías } \\
\text { limpias }\end{array}$ & $\begin{array}{l}\text { Cumple con los parámetros del decre- } \\
\text { to 1594/1984 }\end{array}$ & 18 de abril de 2017 \\
\cline { 1 - 1 } $\begin{array}{l}\text { Con plan de reconversión a tecnologías } \\
\text { limpias }\end{array}$ & & 18 de abril de 2020 \\
\cline { 1 - 1 } $\begin{array}{l}\text { Sin plan de reconversión a tecnologías } \\
\text { limpias }\end{array}$ & $\begin{array}{l}\text { Incumple con los parámetros del de- } \\
\text { creto 1594/1984 }\end{array}$ & 18 de octubre de 2016 \\
\cline { 1 - 1 } $\begin{array}{l}\text { Con plan de reconversión a tecnologías } \\
\text { limpias }\end{array}$ & & 18 de octubre de 2018 \\
\hline
\end{tabular}

Fuente: elaboración propia.

Ahora bien, de acuerdo con los análisis normativos y jurídicos fijados, no es posible realizar el citado conteo desde la fecha de publicación, pues en este punto ni siquiera había entrado en vigencia la resolución 0631/2015, como para que la misma ya iniciara sus efectos jurídicos. Desde un análisis fáctico, si el conteo del régimen de transición empezaba antes de la fecha de entrada en vigor de la resolución 0631/2015, este no beneficiaría a la mayoría de los administrados, pues muchos de ellos únicamente solicitaron sus permisos de vertimiento después de haber conocido dicha norma con la firme intención de poder acceder al régimen de transición. Para desglosar vale la pena hacer un análisis mucho más detallado.

En primer lugar, se debe atender a lo que enuncia el artículo 27 del Código Civil, en el cual se dispone que, si el sentido de la ley es claro, no se hace necesario desatender su tenor literal a pretexto de consultar su espíritu. Pero en aras de interpretar una expresión oscura de la ley, vale recurrir a su intención o espíritu, claramente manifestado en ella misma o en la historia fidedigna de su establecimiento ${ }^{20}$.

20 "[...] según este artículo hay casos fáciles que pueden resolverse mediante un proceso de deducción silogística. La premisa mayor sería la norma, la premisa menor la conducta o hecho de relevancia jurídica y la conclusión es la imposición de una consecuencia jurídica descrita en la norma, para el caso o hecho concreto. Pero al
Sin duda, y a pesar de que pareciera que nos encontramos frente a un caso "fácil", la lectura del artículo 2.2.3.3.11.1 del decreto 1076/2015 no lo es, debido a que sus numerales 1 y 2 parten de la base de que la norma que expediría el Ministerio de Ambiente y Desarrollo Sostenible entraría en vigencia en la misma fecha en que sería publicada.

Para darle sustento a la anterior afirmación, vale la pena resaltar cómo ambos numerales comienzan de la siguiente manera: "Los generadores de vertimiento que a la entrada en vigencia de las normas de vertimiento a que hace referencia el artículo 2.2.3.3.4.7 del presente decreto, tengan permiso de vertimiento vigente expedido con base en la normatividad vigente [...]". Es decir que los mismos presuponen que el régimen de transición es aplicable en este caso, tan solo para aquellos

\footnotetext{
lado de estos casos, más comunes en el derecho penal $y$ en el disciplinario, también hay casos que implican ejercicios más complejos de interpretación. En estos casos denominados oscuros, el intérprete tiene al menos dos posibilidades. La primera es remitirse a los principios contenidos en la misma ley, a fin de buscar en ellos 'la intención o espíritu' que permita entender ese sentido incierto. De esta forma el análisis se circunscribe al plano de la misma ley. La segunda posibilidad es buscar en otras fuentes, distintas a la ley, a fin de determinar el sentido de las expresiones contenidas en ellas" (Quintero, 2008, p. 78).
} 
usuarios que antes del 1 de enero de $2016^{21}$ contaran con permiso de vertimiento vigente.

Por su parte, ambos numerales aseveran que los términos del régimen de transición deberán contarse a partir de la fecha de publicación de la respectiva resolución: 18 de abril de 2015.

Si se estiman los argumentos expuestos, se puede demostrar cómo la primera fecha estipulada tiene como fin verificar si el administrado cuenta con permiso de vertimiento vigente y está cumpliendo con los términos, condiciones y obligaciones que aparecen allí, razón por la que sería imposible asumir que los términos del régimen de transición se deben contar desde el 18 de abril de 2015, pues en ese momento ni siquiera se podía tener conocimiento de quiénes eran acreedores a este beneficio.

Esta posición la ratificó el Ministerio de Ambiente y Desarrollo Sostenible ${ }^{22}$, que manifestó en diferentes oportunidades que los términos de dicho régimen deberán contarse a partir de la fecha de entrada en vigencia de la resolución 0631/2015.

$21 \quad$ A pesar de lo anterior, el Ministerio de Ambiente y Desarrollo Sostenible expidió una prolongación de los plazos establecidos por intermedio de la resolución 2659/2015, promulgada el 29 de diciembre de 2015, en la que manifestó: "Para aquellos usuarios del recurso hídrico que presentaron solicitud de permiso de vertimiento no doméstico al alcantarillado público con el lleno de los requisitos exigidos por el ordenamiento jurídico al momento de su radicación y que al 1 de enero de 2016 el trámite del mismo no ha sido resuelto de fondo por la Autoridad Ambiental, la presente Resolución entrará en vigencia el 1 de mayo de 2016. A efectos de lo anterior, la Autoridad Ambiental Competente deberá resolver de fondo el trámite en curso, a más tardar el 30 de abril de 2016".

22 Textualmente instituyó en concepto emitido por la Oficina Asesora Jurídica el 25 de junio de 2015 que: "La Resolución 631 de 2015 fue publicada en el Diario Oficinal No. 49486 del 18 de abril de 2015. Por su parte, el artículo 21 de la aludida resolución dispone que la misma entra en vigencia a partir del 01 de enero de 2016; de tal forma, que a partir de esta última fecha, empiezan a correr todos los términos definidos en su artículo 19, en concordancia con lo establecido en los artículos 77 y 78 del Decreto 3930 de 2010 (modificados respectivamente por los artículos 7 y 8 del Decreto 4728 de 2010)".
Ahora bien, esta discusión también adquiere relevancia significativa en el entendido que el artículo 2.2.3.3.6.4 establece la posibilidad de presentar planes de reconversión a tecnologías limpias dentro del plazo de un año siguiente a la publicación del acto administrativo.

Si se lee literalmente el artículo, se comprende que los usuarios tenían del 18 de abril de 2015 hasta el 18 de abril de 2016 para entregar planes de reconversión a tecnologías limpias, hecho que de acuerdo con lo expuesto es totalmente ilógico, pues las autoridades ambientales tenían hasta el 30 de abril de 2016 para definir la coyuntura del permiso de vertimiento a algunos usuarios, lo cual haría que se rompiera la igualdad de cargas a los administrados y que de entrada planteara que la fecha de publicación no pudiera ser aquella que se debía tener en consideración.

Así las cosas, vale la pena indicar que la interpretación de la norma de vertimientos, de conformidad con su espíritu, deriva en las tablas 2 y 3 , en donde se muestra la situación de cada uno de los usuarios, según las posibles interpretaciones de dicho régimen.

Se concluye que a pesar de que la norma vigente establezca la fecha de publicación como aquella fecha en la cual se debe iniciar el conteo de los términos del régimen de transición, esta no puede ser la manera como se realice tal conteo, pues la forma correcta debe ser a partir de la entrada en vigor de las resoluciones 0631/2015 (1 de enero de 2016) y 2659/2015 (1 de mayo de 2016).

\section{Conclusiones}

Realizando la recopilación in genere de lo observado, tenemos dos apreciaciones especiales que presentar como conclusiones: unas generales (consecuencia derivada) y otras particulares (consecuencia precisa) de cada uno de los temas tratados. 
Tabla 2. Fechas aplicables para el régimen de transición contadas a partir del 1 de enero de 2016

\begin{tabular}{l|l|l}
\hline $\begin{array}{l}\text { Situación frente al plan de recon- } \\
\text { versión a tecnologías limpias }\end{array}$ & $\begin{array}{c}\text { Estado de cumplimiento del } \\
\text { decreto 1594/1984 }\end{array}$ & $\begin{array}{c}\text { Fecha de entrada en vigencia de } \\
\text { la resolución 631/2015 }\end{array}$ \\
\hline $\begin{array}{lll}\text { Sin plan de reconversión a tecnologías } \\
\text { limpias }\end{array}$ & $\begin{array}{l}\text { Cumple con los parámetros del de- } \\
\text { creto 1594/1984 }\end{array}$ & 1 de enero de 2018 \\
\cline { 1 - 1 } $\begin{array}{l}\text { Con plan de reconversión a tecnologías } \\
\text { limpias }\end{array}$ & & 1 de enero de 2021 \\
\cline { 1 - 1 } $\begin{array}{l}\text { Sin plan de reconversión a tecnologías } \\
\text { limpias }\end{array}$ & $\begin{array}{l}\text { Incumple con los parámetros del de- } \\
\text { creto 1594/1984 }\end{array}$ & 1 de julio de 2017 \\
\cline { 1 - 1 } $\begin{array}{l}\text { Con plan de reconversión a tecnologías } \\
\text { limpias }\end{array}$ & & 1 de julio de 2019 \\
\hline
\end{tabular}

Fuente: elaboración propia.

Tabla 3. Fechas aplicables para el régimen de transición contadas a partir del 1 de mayo de 2016. Únicamente a usuarios que les aplique la resolución 2659/2015

\begin{tabular}{l|l|l}
\hline \multicolumn{1}{c|}{$\begin{array}{c}\text { Situación frente al plan } \\
\text { de reconversión a } \\
\text { tecnologías limpias }\end{array}$} & $\begin{array}{c}\text { Estado de cumplimiento } \\
\text { del decreto 1594/1984 }\end{array}$ & $\begin{array}{c}\text { Fecha de entrada en vigencia de } \\
\text { la resolución 631/2015 conforme } \\
\text { a la prolongación de la } \\
\text { resolución 2659/2015 }\end{array}$ \\
\hline $\begin{array}{lll}\text { Sin plan de reconversión a tecnologías } \\
\text { limpias }\end{array}$ & $\begin{array}{l}\text { Cumple con los parámetros del de- } \\
\text { creto 1594/1984 }\end{array}$ & 1 de mayo de 2018 \\
\cline { 1 - 1 } $\begin{array}{l}\text { Con plan de reconversión a tecnologías } \\
\text { limpias }\end{array}$ & & 1 de mayo de 2021 \\
\hline $\begin{array}{ll}\text { Sin plan de reconversión a tecnologías } \\
\text { limpias }\end{array}$ & $\begin{array}{l}\text { Incumple con los parámetros del de- } \\
\text { creto 1594/1984 }\end{array}$ & 1 de noviembre de 2017 \\
\cline { 1 - 1 } $\begin{array}{l}\text { Con plan de reconversión a tecnologías } \\
\text { limpias }\end{array}$ & & 1 de noviembre de 2019 \\
\hline
\end{tabular}

Fuente: elaboración propia.

Como conclusiones generales tenemos que la deficiente regulación existente en torno a la materia afecta la protección de los recursos naturales renovables.

Recordemos que la adecuada regulación de los vertimientos o desechos líquidos a nuestras fuentes es de vital importancia para el crecimiento del país, acorde con el sostenimiento de la base de nuestros recursos naturales renovables indispensables para la vida. Por esto es un tema de gran relevancia nacional, ya que la contami- nación por vertimientos puede desembocar en la imposibilidad de utilizar nuestras aguas para ingesta, para actividades comerciales, industriales, recreación, turismo y otras.

Por esta razón, una regulación precisa, ordenada, coherente, clara y unificada se requiere para evitar los infortunados estragos que los vertimientos pueden conllevar en la salud humana, animal y en general, en todos los componentes del ambiente. 
No obstante, con la temática expuesta fue posible observar que la regulación ha venido siendo expedida con infinidad de imprecisiones, entre estas:

- Normas antitécnicas al no plantear de modo preciso conceptos, contenidos, transiciones $y$ otros.

- Adiciones y excepciones al contenido de la ley, a través de conceptos de la Oficina Asesora Jurídica del Ministerio de Ambiente y Desarrollo Sostenible.

- Excesivas facultades discrecionales.

Entonces, podemos encontrar que la regulación al tener tantos inconvenientes, no está coadyuvando en la protección de nuestros recursos naturales sino por el contrario, tiene como efecto la inobservancia de la ley o su aplicación selectiva.

Se debe buscar una interpretación uniforme y acorde con la normatividad de superior jerarquía vigente, pues las confusiones en torno a la reglamentación han suscitado diversas interpretaciones que en ocasiones acarrean una incertidumbre jurídica, la cual podría terminar vulnerando el derecho al debido proceso de los administrados. Se hace imprescindible que el Sistema Nacional Ambiental de Colombia se muestre articulado frente a los administrados, pues de ello también depende la eficacia de las normas. Las autoridades ambientales deben buscar interpretaciones uniformes, que no solo respondan a las necesidades ambientales del país, sino que brinden seguridad y confianza jurídica, en un modelo normativo ambiental que cada día afronta nuevos retos frente al desarrollo sostenible de las organizaciones. No debemos olvidar lo que consigna el documento Conpes 3343:

Colombia enfrenta retos importantes en términos de degradación ambiental que comprometen su desarrollo económico sostenible. Estudios preliminares sobre los costos de degradación ambiental en Colombia, indican que los impactos más considerables están asociados con la contaminación del agua [...], las inadecuadas condiciones del agua, el saneamiento y la higiene [...] se ha encontrado que la degradación ambiental afecta significativamente la salud de niños y adultos mayores, la población más pobre y grupos más vulnerables (Departamento Nacional de Planeación, 2005, p. 1).

Así las cosas, la dispersión normativa e interpretativa evidenciada a lo largo de todo el texto, hace pensar que es necesario replantear varios escenarios que, si bien pudieran ser complejos y riesgosos, sin duda buscarían el acatamiento de las disposiciones constitucionales sobre la protección de los recursos, y no únicamente serían el resultado de interpretaciones aisladas, sobre bases hipotéticas y no normativas.

Es clara entonces la necesidad sentida que tiene el país frente a esta regulación, lo cual nos llevaría sin duda a un escenario de protección de los derechos colectivos y de los derechos asociados a la eficacia de las normas.

Como conclusiones particulares tenemos dos: la primera en relación con la necesidad o no de contar con permiso de vertimientos y la segunda respecto a los regímenes de transición. Sobre el permiso de vertimientos tenemos hoy en día vigentes las siguientes fuentes jurídicas:

- El artículo 2.2.3.3.5.1 del decreto 1076/2015 que expresa que requieren permiso de vertimientos quienes realicen la descarga de residuos principalmente líquidos al suelo, la mar y las aguas superficiales (norma que no incluye el alcantarillado).

- Un concepto de la Oficina Asesora Jurídica (8140e227306 del 12 de septiembre de 2014) que sostiene que sí se requiere permiso cuando el vertimiento se realice al alcantarillado. Modificando así el decreto del sector ambiente.

- Un concepto de la Oficina Asesora Jurídica (8140-E2-23685 del 30 de julio de 2015) que manifiesta que no siempre se exige permiso de vertimientos cuando la descarga se haga 
al sistema de alcantarillado. Únicamente se requerirá cuando esta descarga no sea doméstica. En otras palabras, los suscriptores domésticos como casas y apartamentos habitacionales no necesitan este permiso, los demás sí.

Del examen de las fuentes precitadas tenemos que se presenta como problemática que existe un cruce entre estas variables en la vida práctica, como lo pueden ser:

- Usuarios que de la lectura de la norma entienden que no requieren permiso de vertimientos y por ende no lo solicitan. En caso de estar en jurisdicción de una autoridad ambiental que entienda lo mismo, no pasará nada. Pero en caso de entender la autoridad ambiental que sí requiere el permiso, habrá acciones sancionatorias.

- Usuarios que de la lectura de los conceptos del Ministerio de Ambiente y Desarrollo Sostenible coligen que deben obtener permiso de vertimientos. En caso de estar en jurisdicción de una autoridad ambiental que entienda que no lo requieren habrán realizado un desgaste en tiempo y monetario innecesario. Pero, si la autoridad ambiental conoce los conceptos del Ministerio, tramitará y otorgará el permiso.

- Usuarios o suscriptores domésticos que deduzcan que el concepto del Ministerio de Ambiente y Desarrollo Sostenible sobre la obligatoriedad de obtener permiso de vertimientos les es vinculante y soliciten el permiso. En caso de estar en jurisdicción de una autoridad ambiental que comprenda que no lo requieren habrán realizado un desgaste en tiempo y monetario innecesario. Pero, si la autoridad ambiental conoce este concepto del Ministerio, tramitará y otorgará el permiso; pudiendo además exigir a todos los suscriptores domésticos del sistema el permiso ambiental. Téngase igual premisa para los usuarios industriales.
Así pues, estas opciones interpretativas hacen que tengamos vertimientos altamente contaminantes sin control, vertimientos inofensivos hipervigilados (con permiso y otras exigencias), entre muchas variables que pudiesen presentarse en una investigación más amplia.

Por esto, es una necesidad que se adopten medidas urgentes para ajustar la normativa, de tal manera que responda a criterios de unidad, coherencia y claridad.

Ahora bien, como segunda conclusión particular tenemos que las autoridades ambientales deberán considerar las fechas del 1 de enero de 2016 o 1 de mayo de 2016, las cuales darán el punto de partida para asumir el conteo de los términos fijados. En todo caso, se reitera que la fecha de publicación de la resolución 0631/2015 (estipulada en el derogado decreto 3930/2010) no puede ser tenida en cuenta por las autoridades ambientales, conforme a los análisis adelantados.

Dicha confusión es innecesaria, porque el Ministerio de Ambiente y Desarrollo Sostenible debió prever la existencia de la misma y, en consecuencia, aclarar las fechas desde la expedición de la norma y no vía concepto como se ha venido haciendo, pues lo mismo pone en una situación incierta a las autoridades ambientales, quienes con base en la interpretación de la ley pueden asumir criterios diferenciales, dependiendo de su análisis particular.

\section{Referencias}

Consejo de Estado, Sala de lo Contencioso Administrativo, Sección Primera. (2011). Auto del 13 de octubre. C. P.: Rafael E. Ostau de Lafont Pianeta. Radicación 11001 032400020110024500.

Corporación Autónoma Regional de Cundinamarca. (2006). Guía para la formulación del plan de saneamiento y manejo de vertimientos. Bogotá: Corporación Autónoma Regional de Cundinamarca. 
Corporación Autónoma Regional del Valle del Cauca. (2015). Concepto 0110-05214910-2015.

Corporación Autónoma Regional del Valle del Cauca (2016) . Concepto No. 0110830142016.

Corte Constitucional de Colombia. (1999). Sentencia C-957. M. P.: Álvaro Tafur Galvis.

Corte Constitucional de Colombia. (2006). Sentencia C-932. M. P.: Humberto Antonio Sierra Porto.

Departamento Nacional de Planeación. (2005). Documento Conpes 3344. Lineamientos y estrategias de desarrollo sostenible para los sectores de agua, ambiente y desarrollo territorial. Bogotá: DNP.

Escobar, J. (2002). La contaminación de los ríos y sus efectos en las áreas costeras y el mar. Santiago de Chile: Cepal, División de Recursos Naturales e Infraestructura, Serie Recursos Naturales e Infraestructura.

Gómez-Rey, A., Rincón, C. \& Rodríguez, G. (2016). Los regímenes de transición del licenciamiento ambiental en Colombia vistos desde la actividad minera. Revista Prolegómenos Derechos y Valores, 19(38), 161-181. DOI: http://dx.doi.org/10.18359/ prole.1976
González, J. E. (2004). Los vertimientos en Colombia y su regulación. Derecho de aguas. Tomo II. Bogotá: Universidad Externado de Colombia.

Macías, L. F. (1998). Introducción al derecho ambiental. Bogotá: Legis.

Ministerio de Ambiente y Desarrollo Sostenible. (2014). Concepto 8140e227306.

Ministerio de Ambiente y Desarrollo Sostenible. (2015). Concepto 8140-E2- 23685.

Morales, M. V. (1999). Los servicios públicos domiciliarios y su contenido ambiental. Lecturas sobre derecho del medio ambiente. Tomo I. Bogotá: Universidad Externado de Colombia.

Quintero, D. P. (2008). Introducción al derecho ambiental, aspectos teórico-prácticos. Cali: Colección Discernir, Universidad Icesi.

Real Academia Española. (2016). Definición de "régimen" y "transición". Disponible en: http://dle.rae. es/?id=ViiZ39k

Rodríguez, G. A., Lozano, C. \& Gómez-Rey, A. (2011). La protección jurídica del agua en Colombia. Bogotá: Grupo Editorial Ibáñez.

Santander, E. (2002). Instituciones de derecho ambiental. Bogotá: Ecoe Ediciones. 